\title{
Sports Injuries among Professional Male Athletes in Kuwait: Prevalence and Associated Factors
}

\author{
Yousef Marwan Abdullah Behbehani Abdullah Al-Mousawi Ali Mulla-Juma'a \\ Husain Sadeq Nasrah Shah \\ Department of Community Medicine and Behavioral Sciences, Faculty of Medicine, Health Sciences Centre, \\ Kuwait University, Al-Jabriya, Kuwait
}

\section{Key Words}

Sports injuries $\cdot$ Soccer $\cdot$ Basketball $\cdot$ Handball $\cdot$ Volleyball . Male athletes

\begin{abstract}
Objectives: To assess a 12-month period and the lifetime prevalence of sports injuries among male athletes according to type of sport, type of injury and its seriousness, and to examine the association of injuries with sociodemographic, lifestyle and preventive factors. Subjects and Methods: In this cross-sectional study, we approached 475 professional athletes participating in ball sports, aged 15 years and older, from 5 sports clubs in Kuwait. Of them, 452 responded. Four ball games - football (soccer), basketball, handball and volleyball - were included. Data were collected through a self-administered questionnaire. Bivariate and multivariate relationships between associated factors and experience of injury were tested by using $\chi^{2}$ and logistic regression. Results: The overall 12-month and lifetime prevalence of sports injuries were 73.8 and $89.8 \%$, respectively. Prevalence was highest among volleyball athletes (79\%) and lowest among football (soccer) athletes (69\%). Lower limbs (73.1\%) were the most common site of injuries and joint injuries $(43.6 \%)$ were the most common type. For the most recent injury, 138 (42\%) of athletes took more than 10 days
\end{abstract}

off practice. Compared to volleyball, football (soccer) and handball athletes were 2.9 times $(95 \% \mathrm{Cl}: 1.3-6.3)$ and 3.4 times (95\% Cl: $1.5-7.8)$ more likely to take more than 10 days off practice. Athletes who sometimes wore protective gears were 3.1 times (95\% Cl: 1.7-5.8) more likely to report an injury compared with those who never wore protective gears $(p<0.001)$. Conclusions: Sports injuries are highly prevalent among professional athletes in Kuwait. Future studies are needed to provide guidelines for interventions that may reduce such injuries.

Copyright $\odot 2011$ S. Karger AG, Basel

\section{Introduction}

For centuries, it has been recognized that both recreational and professional sports have a greatly positive effect on human health. However, sports-related injuries can be potentially harmful to both individual and society. A sports injury may be defined as any injury occurring during a scheduled match or training session causing the player to seek medical attention or miss part of the next match or training session [1]. Morbidity from injuries in young populations is substantial all over the world and recreational and sports injuries represent major risks for young people [2].

\section{KARGER}

Fax +41613061234 E-Mail karger@karger.ch www.karger.com
(C) 2011 S. Karger AG, Base

$1011-7571 / 12 / 0212-0171 \$ 38.00 / 0$

Accessible online at:

www.karger.com/mpp
Mr. Yousef Marwan

Department of Community Medicine and Behavioral Sciences

Faculty of Medicine, Health Sciences Centre, Kuwait University

PO Box 24923, Safat 13110 (Kuwait)

Tel. +9659406 0660, E-Mail marwan@ @sc.edu.kw 
Many studies have been conducted on the prevalence and incidence of sports injuries. It has been estimated that 3.7 million people present to emergency departments in the USA with an injury related to sport and exercise each year [3]. In Denmark, a prospective study of $302 \mathrm{ad}-$ olescent players in three ball games (football/soccer, handball and basketball) reported 119 injuries, in which the injury incidence (per 1,000 playing hours) was 5.6 in football (soccer), 4.1 in handball, and 3.0 in basketball [4]. In Germany, $62 \%$ of all sports injuries result in sick leave; the period off work was longer than 30 days in 1 out of 5 cases [5]. The incidence of injury was reported to be higher in the contact sports, such as Australian football and basketball, compared to non-contact sports, such as netball [6].

Regarding sports injuries in Kuwait, only one study conducted on recreational football (soccer) players had been reported and the yearly prevalence was $86.6 \%$ [7]. Because there is a shortage of data about sports injuries among professional sports athletes in Kuwait, we decided to assess the 12-month period and the lifetime prevalence of sports injuries among male athletes according to type of sport, type of injury, and seriousness of injury, examine the association between sports injuries and sociodemographic characteristics, lifestyle factors and the use of protective gears, and assess the need for providing interventions to prevent sports injuries.

\section{Subjects and Methods}

\section{Sample Size Determination}

An assumed proportion of 0.65 of our main outcome, sports injury history during the previous 12 months was used to calculate the required sample size with allowed error (effect size $\delta$ ) of 0.15 in either direction. The estimated required sample size was 126 athletes based on type I error $(\alpha)$ of 0.05 and a test power of 0.95 (i.e. type 2 error, $\beta=0.05$ ). However, it was decided to approach more than 400 athletes so that we would be able to compare different types of sports.

\section{Selection of Participants}

The study population included male athletes, aged 15 years and older, targeted in 5 of the 14 official sports clubs in Kuwait. This age group was chosen because, according to the 'Public Authority of Youth and Sport', the majority of athletes younger than 15 years were not professionals and they did not practice sports for a period of 12 months to provide sufficient information for analysis. The following ball games were included: football (soccer), handball, basketball and volleyball. These games were chosen because of their popularity in Kuwait and the fact that they have the largest number of players.

To choose which clubs to include in the study, the 'Public Authority of Youth and Sport' was contacted to learn which clubs have teams of these 4 games. It appeared that 10 out of the 14 clubs have these games. However, only 5 clubs had athletes that met the age selection criterion of 15 years or older. These 5 clubs were AlQadsiya, Al-Arabi, Al-Kuwait, Al-Jahra, and Kazma. In these clubs, a total of 475 athletes were approached, of whom 452 agreed to participate.

\section{Tools and Instruments}

A questionnaire was created after an extensive review of the literature. It was developed in English and translated into Arabic using simple and clear words that could convey the same meaning as the English counterparts. Copies of the English and Arabic versions were reviewed by 2 specialists in sports injuries and their suggestions were incorporated in the questionnaires. Both versions were pretested among 21 athletes in Al-Salmiya Sports Club.

The questionnaire included 37 questions under four main categories: (I) sociodemographic characteristic, (II) general health status and lifestyle, (III) sports behavior and practice, and (IV) injuries-related questions. Part I included questions about age, nationality, marital status, education level, occupation, and income from the club and other sources of income. Part II included questions about height, weight, self-reported stress level, physical fitness, chronic diseases and smoking. Body mass index (BMI) was calculated on the basis of the self-reported weight and height of the players, and was classified into underweight $(<18.5)$, normal weight (18.5-24.9) and overweight/obese ( $\geq 25)$. In part III, questions were asked about the nature of the sport, the years and weekly hours of practice, use of protective gears, and receiving regular educational sessions from the club regarding the prevention of sports injuries. The last part of the questionnaire started by defining sports injury as any injury occurring during a scheduled match or training session causing the player to seek medical attention or miss part of the next match or training session. This part included injury-related questions about lifetime history of injury and whether or not an injury was sustained during the previous 12 months. Twelve months' duration was chosen because, according to Gabbe et al. [8], a duration longer than 12 months of recalling sports injuries has a low validity, especially in terms of remembering the diagnosis. Other questions concerned the frequency, occasion (during practice session or official match), site, type and seriousness (measured by the number of days taken off practice) of injury. Also in this part, we asked specifically about the 3 most recent injuries the athletes suffered from during the previous 12 months so that we could estimate the 1-year prevalence of the most common injuries.

The study was approved by the Ethics Committee of the Faculty of Medicine, Kuwait University. Furthermore, the administrators of the participating clubs permitted the research team to collect data from athletes in their clubs. Participants were assured that the data would be used confidentially (anonymous questionnaire). An informed consent (written and verbal) was obtained from each athlete to join the study. For athletes younger than 18 years old, consent was obtained from their parents as well.

\section{Data Collection and Analysis}

Data collection started on April 1st and ended on April 8th, 2010. Athletes were approached during their practice session. The questionnaires were administered either before or after practice, depending upon the preference of the team's trainers. 
After reviewing the frequencies of the prevalence, number, and site of injuries, multivariate analysis using logistic regression was conducted on two main outcome variables. These were history of injury during the previous 12 months (no, yes), and severity of the most recent injury (i.e. $\leq 10$ days taken off practice, $>10$ days taken off practice).

The independent predictors included in the logistic regression were age, nationality, occupation, BMI, type of sport, practice hours per week and the use of protective gears. These variables were included in the regression model because some of them were found to be significant in the crude analyses and others were found to be associated with sports injuries in previous studies [2-7, 9-11]. For both outcome variables, age and type of sport were considered as the most important associated factors. The other variables then were added one at a time to ascertain if they were independently associated with the frequency or seriousness of injury after controlling for age and type of sport.

\section{Results}

\section{Characteristics of Athletes}

More than half of the participants ( $\mathrm{n}=211 ; 50.8 \%)$ were 18 years old or younger, while the remaining $(\mathrm{n}=$ $204 ; 49.2 \%$ ) were older (mean age $=20.01 \pm 4.77$ ). A majority of the participants $(n=396 ; 88.0 \%)$ were Kuwaitis. In terms of BMI, $23(6.0 \%)$ of the participants were underweight, 283 (73.5\%) were within normal range, and 79 $(20.5 \%)$ were overweight or obese $($ mean $=23.1 \pm 3.4)$. Regarding stress level, 30 (6.7\%) athletes reported having high stress level in their lives. 343 (76.2\%) athletes reported that they do not currently smoke. A substantial number of our sample $(n=169 ; 41.0 \%$ ) had been playing for $6-10$ years. Most athletes $(n=337 ; 75.4 \%)$ practiced their sport 10-15 h per week. Regarding protective gears, 240 $(53.2 \%)$ athletes reported wearing it sometimes, 132 (29.3\%) always and 79 (17.5\%) never. The majority of our sample ( $\mathrm{n}=379 ; 83.8 \%$ ) did not receive any educational sessions regarding prevention of sports injuries.

A majority of the participants, 207 (43.6\%) were in the football (soccer) group, while $78(16.4 \%)$ were in the basketball group, 103 (21.7\%) in the handball group and 64 $(13.5 \%)$ in the volleyball group. The youngest players were football/soccer athletes (mean age $=19.2$ ). Surprisingly, 55 (52.9\%) handball athletes were overweight or obese. The highest stress level was among basketball athletes; 11 (14.3\%) reported a high stress level in their life. The proportions of current smokers in handball and volleyball were the highest, 37 (35.5\%) and 22 (34.4\%), respectively. Concerning years of play in a professional club, a large number of the participants played for 6-10 years in their respective clubs. Most of the athletes practiced sports for

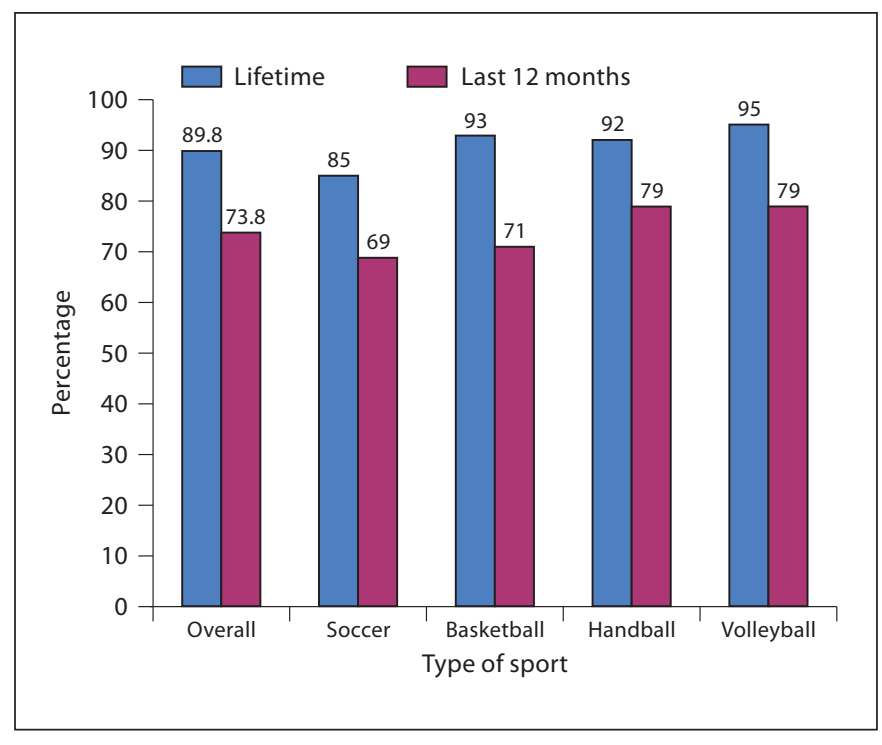

Fig. 1. Percent of ball games athletes who sustained an injury during their lifetime or the previous 12 months in Kuwait, 2010.

10-15 h per week. A much larger number of participants of football (soccer) and basketball athletes, 79 (38.3\%) and $26(33.3 \%)$, respectively, reported that they always wore protective gears compared with only about $17 \%$ of the handball $(n=17)$ or volleyball $(n=11)$ athletes.

\section{Experience of Injury}

The percentage of ball games for athletes who sustained an injury during the previous 12 months or their lifetime is shown in figure 1. Our study showed that 405 $(89.8 \%)$ athletes had sustained a sports injury during their lifetime, while about three quarters $(n=332 ; 73.8 \%)$ of them had sustained an injury during the previous 12 months. Volleyball athletes reported the highest percentage of sports injuries both during the previous 12 months and throughout their lifetime whereas football (soccer) athletes reported the lowest prevalence in both categories. About one quarter $(n=102 ; 22.6 \%)$ of the participants had sustained three or more injuries during the previous 12 months. The number of injuries sustained by the athletes during the previous 12 months is shown in figure 2 .

In terms of the site of the most recent injury, shown in table 1 , lower limbs appeared to be the most common site ( $\mathrm{n}=241 ; 73.1 \%$ ), while the head and neck were the least common ( $\mathrm{n}=17 ; 5.2 \%)$. Joint injuries were the most common type ( $\mathrm{n}=143 ; 43.6 \%)$, followed by muscle strains $(n=91 ; 27.7 \%)$, bruises $(n=88 ; 26.7 \%)$, fractures $(n=17$; 
Table 1. Site, type and days taken off practice for the 3 most recent injuries that occurred during the previous 12 months among ball games athletes in Kuwait, 2010

\begin{tabular}{lccc}
\hline Characteristic & Injury & & \\
\cline { 2 - 4 } & $\begin{array}{c}\text { most recent } \\
(\mathrm{n}=329)\end{array}$ & $\begin{array}{l}\text { 2nd most recent } \\
(\mathrm{n}=226)\end{array}$ & $\begin{array}{l}\text { 3rd most recent } \\
(\mathrm{n}=101)\end{array}$ \\
\hline Site of injury & & & \\
Head/neck & $17(5.2)$ & $10(4.4)$ & $4(4.0)$ \\
Upper limbs & $28(8.6)$ & $35(15.5)$ & $21(20.8)$ \\
Lower limbs & $241(73.1)$ & $153(67.7)$ & $62(61.4)$ \\
Trunk/back & $41(12.5)$ & $26(11.5)$ & $14(13.9)$ \\
Other & $2(0.6)$ & $2(0.9)$ & $0(0.0)$ \\
Type of injury (\% yes) & & \\
Muscle strain & $91(27.7)$ & $55(24.3)$ & $24(23.8)$ \\
Bruise & $88(26.7)$ & $89(39.4)$ & $29(28.7)$ \\
Concussion & $3(0.9)$ & $3(1.3)$ & $0(0.0)$ \\
Joint injury & $143(43.6)$ & $74(32.7)$ & $43(42.6)$ \\
Fracture & $17(5.2)$ & $10(4.4)$ & $3(3.0)$ \\
Other & $11(3.3)$ & $11(4.9)$ & $0(0.0)$ \\
Days taken off practice & & \\
$<1$ & $22(6.8)$ & $19(8.5)$ & $8(7.9)$ \\
$1-10$ & $169(51.2)$ & $127(56.1)$ & $57(56.4)$ \\
$11-30$ & $89(26.9)$ & $54(23.8)$ & $23(22.8)$ \\
$31-60$ & $19(5.9)$ & $14(6.3)$ & $8(7.9)$ \\
$61-90$ & $8(2.5)$ & $7(3.1)$ & $2(2.0)$ \\
$>90$ & $22(6.8)$ & $5(2.2)$ & $3(3.0)$ \\
\hline
\end{tabular}

Figures in parentheses are percentages.

${ }^{1}$ Other sites included groin and teeth. ${ }^{2}$ Joint injuries include dislocations, ligament and cartilage injuries. ${ }^{3}$ Other types of injuries included tooth injuries, muscle spasm and nose bleeding.

$5.2 \%)$, and concussion $(\mathrm{n}=3 ; 0.9 \%)$. The majority of the athletes $(n=191 ; 58 \%)$ had to stop their practice for 10 days or less during their most recent injury, while the rest had to stop for 11 days or more.

\section{Factors Associated with Injury}

Cross-tabulations (not shown) of various background factors with prevalence of injury during the previous 12 months showed that none of the sociodemographic characteristics, general health status and lifestyle factors were significantly associated with experience of an injury. Wearing protective gears was positively associated with the 12 months' history of injury ( $\mathrm{p}=0.002) ; 193(80.8 \%)$ of those who sometimes wore protective gears reported an injury compared with 51 (64.6\%) of those who never wore protective gears.

The crude and adjusted odds ratios of predictors for the history and seriousness of injury during the previous 12 months are shown in tables 2 and 3 . We found that

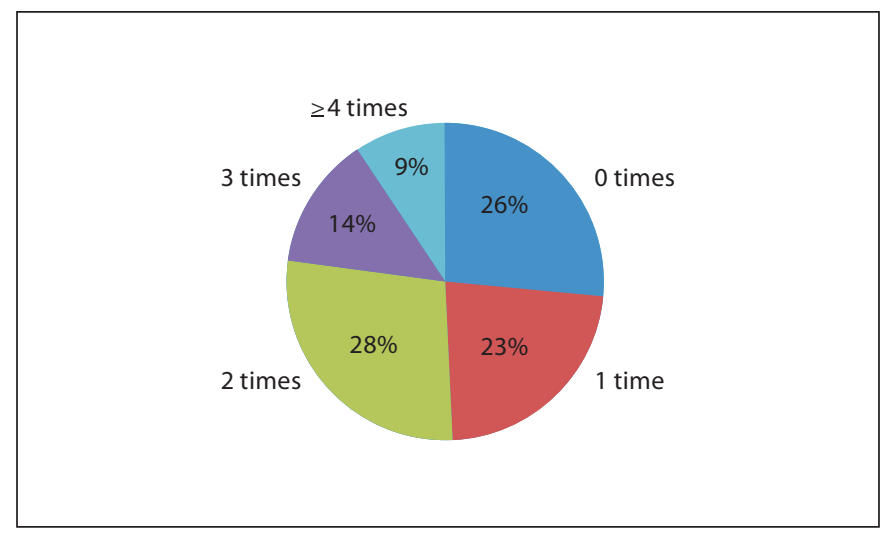

Fig. 2. The number of injuries suffered by ball games athletes during the previous 12 months in Kuwait, 2010.

after adjusting for other variables, those who sometimes wore protective gears were 3.1 times (95\% CI: 1.7-5.8) more likely to have reported an injury compared to those who never wore protective gears $(\mathrm{p}<0.001)$. Also, compared to volleyball athletes, football (soccer) and handball athletes appeared to be 2.9 times $(\mathrm{p}=0.005$, 95\% CI: $1.3-6.3$ ) and 3.4 times ( $\mathrm{p}=0.003,95 \%$ CI: $1.5-$ 7.8) more likely to take more than 10 days off practice due to injury (table 3). The crude odds ratio indicated that non-Kuwaiti athletes were $60 \%$ less likely to take more than 10 days off practice $(\mathrm{p}=0.034)$. This result remained marginally significant after adjusting for other variables $(p=0.052)$. None of the other variables were significantly associated with the frequency or severity of injury.

\section{Discussion}

\section{Prevalence of Injury}

Both previous 12-month and lifetime prevalence of sports injuries were high, 73.8 and $89.8 \%$, respectively. When comparing the prevalence of sports injuries in the previous 12 months among the four ball games, it appeared that volleyball and handball had the highest prevalence (79\%), followed by basketball (71\%), and football (soccer) (69\%). Even though football (soccer) athletes reported the lowest prevalence of injuries, they suffered from more serious injuries, as discussed later. A possible reason for the lower prevalence of injuries in football (soccer) compared to other sports is that this sport is the most popular in Kuwait. It was observed that there was an increased attention and funding from the clubs' ad- 
Table 2. Logistic regression of the 12 months' history of injury among ball games athletes in Kuwait, 2010

\begin{tabular}{|c|c|c|c|c|c|}
\hline \multirow[t]{2}{*}{ Characteristic } & \multirow{2}{*}{$\begin{array}{l}\text { Subgroup } \\
\mathrm{n}(\%)\end{array}$} & \multicolumn{2}{|c|}{ Univariate logistic regression } & \multicolumn{2}{|c|}{ Multivariate logistic regression } \\
\hline & & $\begin{array}{l}\text { crude OR } \\
(95 \% \text { CI })\end{array}$ & $\mathrm{p}$ value & $\begin{array}{l}\text { adjusted OR } \\
(95 \% \mathrm{CI})\end{array}$ & $\mathrm{p}$ value \\
\hline \multicolumn{6}{|l|}{ Age, years } \\
\hline$\leq 18$ & $211(51)$ & 1.0 & & 1.0 & \\
\hline$>18$ & $203(49)$ & $0.9(0.6-1.5)$ & 0.985 & $0.9(0.6-1.4)$ & 0.854 \\
\hline \multicolumn{6}{|l|}{ Nationality } \\
\hline Kuwaiti & $394(88)$ & 1.0 & & 1.0 & \\
\hline Non-Kuwaiti & $54(12)$ & $0.8(0.4-1.5)$ & 0.559 & $0.9(0.4-1.7)$ & 0.755 \\
\hline \multicolumn{6}{|l|}{ Occupation } \\
\hline Student & $296(66)$ & 1.0 & & 1.0 & \\
\hline Employed & $120(27)$ & $0.9(0.6-1.5)$ & 0.947 & $1.4(0.7-2.8)$ & 0.271 \\
\hline Unemployed & $34(7)$ & $1.1(0.5-2.6)$ & 0.723 & $1.5(0.6-3.9)$ & 0.367 \\
\hline \multicolumn{6}{|l|}{ BMI } \\
\hline Underweight & $23(6)$ & 1.0 & & 1.0 & \\
\hline Normal weight & $282(74)$ & $2.2(0.9-5.2)$ & 0.074 & $2.0(0.8-5.1)$ & 0.116 \\
\hline Overweight/obese & $78(20)$ & $2.2(0.8-5.8)$ & 0.104 & $1.9(0.6-5.9)$ & 0.245 \\
\hline \multicolumn{6}{|l|}{ Type of sport } \\
\hline Volleyball & $63(14)$ & 1.0 & & 1.0 & \\
\hline Soccer & $206(46)$ & $0.6(0.3-1.1)$ & 0.604 & $0.6(0.3-1.2)$ & 0.174 \\
\hline Basketball & $78(17)$ & $0.6(0.3-1.4)$ & 0.302 & $0.6(0.2-1.3)$ & 0.215 \\
\hline Handball & $103(23)$ & $1.0(0.4-2.2)$ & 0.970 & $1.1(0.5-2.5)$ & 0.753 \\
\hline \multicolumn{6}{|c|}{ Hours of practice/week } \\
\hline$<10$ & $85(19)$ & 1.0 & & 1.0 & \\
\hline$\geq 10$ & $360(81)$ & $1.2(0.7-2.1)$ & 0.345 & $1.3(0.7-2.3)$ & 0.252 \\
\hline \multicolumn{6}{|l|}{ Protective gears } \\
\hline Never & $79(18)$ & 1.0 & & 1.0 & \\
\hline Sometimes & $239(53)$ & $2.3(1.3-4.0)$ & 0.004 & $3.1(1.7-5.8)$ & $<0.001$ \\
\hline Always & $131(29)$ & $1.1(0.6-2.0)$ & 0.698 & $1.4(0.7-2.7)$ & 0.250 \\
\hline
\end{tabular}

The first odds ratio (OR) number in each variable is the reference number for that variable.

ministrations for football (soccer), which might have resulted in better preventive measures, such as good protective gears, high-quality training programs, and athletes' education on how to prevent recurrence of injuries, hence, an improved prevention of injuries.

Our findings regarding the lowest prevalence of injuries in football (soccer) were in contrast to that reported in the study by Yde and Nielsen [4] in which the incidence of injury was highest in football (soccer) (5.6/1,000 playing hours) followed by handball (4.1/1,000 playing hours), then basketball (3.0/1,000 playing hours). Yde and Nielsen [4] did not include volleyball athletes, and enrolled male as well as female athletes aged 7-14 years old. The differences in sampling might have contributed to the difference between our study and theirs. Also, a study by AlHadlaq et al. [7] found the prevalence of injuries among recreational football (soccer) players in Kuwait to be $86.6 \%$, while professional soccer athletes in our study re- ported a lower percentage of injuries (69\%). The difference of prevalence between recreational and professional football (soccer) athletes is probably due to the fact that professional athletes are continuously training under supervision and have better preventive measures against injuries. The above explanation is supported by a study in Australia, where the risk of injury was reduced by $32 \%$ if athletes had undertaken a training program designed by sports professionals [6].

Type, Site, and Seriousness of Injuries

Our findings of $43.6 \%$ showed that the most common type of recent injury was joint injuries (i.e. dislocations, ligaments and cartilage injuries), which confirmed a German study [9].

Also, our finding that the majority of the injuries occurred in lower limbs (73.1\% for the most recent injury) is consistent with that of Yde and Nielsen [4], who report- 
Table 3. Logistic regression of the seriousness (defined as stopping practice for more than 10 days) of the most recent injury during the previous 12 months among ball games athletes in Kuwait, 2010

\begin{tabular}{|c|c|c|c|c|c|}
\hline \multirow[t]{2}{*}{ Characteristic } & \multirow{2}{*}{$\begin{array}{l}\text { Subgroup } \\
\mathrm{n}(\%)\end{array}$} & \multicolumn{2}{|c|}{ Univariate logistic regression } & \multicolumn{2}{|c|}{ Multivariate logistic regression } \\
\hline & & $\begin{array}{l}\text { crude OR } \\
(95 \% \mathrm{CI})\end{array}$ & $\mathrm{p}$ value & $\begin{array}{l}\text { adjusted OR } \\
(95 \% \mathrm{CI})\end{array}$ & $\mathrm{p}$ value \\
\hline \multicolumn{6}{|l|}{ Age, years } \\
\hline$\leq 18$ & $149(51)$ & 1.0 & & 1.0 & \\
\hline$>18$ & $147(49)$ & $1.4(0.9-2.3)$ & 0.103 & $1.5(0.9-2.4)$ & 0.075 \\
\hline \multicolumn{6}{|l|}{ Nationality } \\
\hline Kuwaiti & $284(88)$ & 1.0 & & 1.0 & \\
\hline Non-Kuwaiti & $38(12)$ & $0.4(0.2-0.9)$ & 0.034 & $0.4(0.1-1.0)$ & 0.052 \\
\hline \multicolumn{6}{|l|}{ Occupation } \\
\hline Student & $212(65)$ & 1.0 & & 1.0 & \\
\hline Employed & $86(27)$ & $1.2(0.7-2.0)$ & 0.363 & $0.9(0.4-1.9)$ & 0.859 \\
\hline Unemployed & $26(8)$ & $1.5(0.6-3.4)$ & 0.302 & $1.3(0.5-3.5)$ & 0.564 \\
\hline \multicolumn{6}{|l|}{ BMI } \\
\hline Underweight & $13(5)$ & 1.0 & & 1.0 & \\
\hline Normal weight & $206(75)$ & $1.1(0.3-3.5)$ & 0.842 & $1.0(0.2-3.3)$ & 0.998 \\
\hline Overweight/obese & $57(20)$ & $1.5(0.4-5.2)$ & 0.489 & $1.1(0.2-4.4)$ & 0.893 \\
\hline \multicolumn{6}{|l|}{ Type of sport } \\
\hline Volleyball & $49(15)$ & 1.0 & & 1.0 & \\
\hline Soccer & $142(44)$ & $2.9(1.3-6.1)$ & 0.005 & $2.9(1.3-6.3)$ & 0.005 \\
\hline Basketball & $56(17)$ & $1.6(0.6-3.9)$ & 0.270 & $1.4(0.5-3.6)$ & 0.417 \\
\hline Handball & $77(24)$ & $4.1(1.8-9.2)$ & 0.001 & $3.4(1.5-7.8)$ & 0.003 \\
\hline \multicolumn{6}{|l|}{ Hours of practice/week } \\
\hline$<10$ & $57(18)$ & 1.0 & & 1.0 & \\
\hline$\geq 10$ & $262(82)$ & $1.4(0.7-2.5)$ & 0.266 & $1.5(0.8-3.0)$ & 0.164 \\
\hline \multicolumn{6}{|l|}{ Protective gears } \\
\hline Never & $48(15)$ & 1.0 & & 1.0 & \\
\hline Sometimes & $189(58)$ & $0.8(0.4-1.6)$ & 0.614 & $0.8(0.4-1.6)$ & 0.625 \\
\hline Always & $87(27)$ & $0.7(0.3-1.6)$ & 0.528 & $0.8(0.3-1.8)$ & 0.672 \\
\hline
\end{tabular}

The first odds ratio (OR) number in each variable is the reference number for that variable.

ed that $76 \%$ of injuries occurred in the lower limbs. The possible explanation for the high frequency of injuries in the lower limbs is that all of the four ball games require an intensive use of this region of the body, thus predisposing it to injury.

Regarding the seriousness of injuries, athletes in $\mathrm{Ku}-$ wait were found to be similar to athletes in Germany, where more than $10 \%$ of them required more than 30 days off practice after sustaining a sport injury [5]. These results indicate that a large proportion of sports injuries are severe and emphasize the physical and economic burden of sports injuries.

\section{Injury-Associated Factors}

We found that age was not significantly associated with the history or severity of injuries contrary to the findings of Schneider et al. [9], who reported that the in- cidence of sports injuries declined noticeably in older age groups. This discrepancy could be a result of differences in the samples of our study and theirs, which included male and female adults aged 18-79 years of age, and was not restricted to professional athletes. The age of our participants ranged from 15 to 33 years. Moreover, lifestyle factors (e.g. smoking and obesity) were not found to be associated with sustaining injuries or seriousness of injuries. While obesity and smoking are known risk factors for many chronic diseases, such as heart and lung disease, they are not proven to be direct causes of trauma such as sports injuries.

Following injury, it was noted that Kuwaiti athletes took more days off practice compared to non-Kuwaiti athletes. This could be due to the fact that the majority of the non-Kuwaiti athletes do not receive any income other than the club income while Kuwaiti athletes do. Non- 
Kuwaiti athletes therefore need to resume playing as soon as possible to avoid any salary cut.

In the multivariate analysis, handball and football (soccer) athletes reported more serious injuries compared to volleyball players (OR 3.4 and OR 2.9, respectively). This result may be attributable to the different context of each sport, such as the amount of contact between athletes, intensity of the physical activity, and rules and regulations for the particular sport. For example, volleyball teams do not come in contact during the match except on some occasions when a player lands on the foot of an opposing player within the conflict zone, while handball and soccer teams come into contact frequently throughout the match, leading to a greater likelihood of sustaining more severe injuries.

In contrast to what was found by Aaltonen et al. [10] and Emery [11], sustaining an injury was found to be positively associated with wearing protective gears in our sample of athletes. While surprising, these findings might have resulted from the cross-sectional design of this study that could not establish a temporal relationship. In fact, during data collection it was observed that a large number of athletes wore protective gears after sustaining an injury. Thus, preventive behavior could have been motivated by the experience of an injury.

\section{Conclusion}

The prevalence of sports injuries during the previous 12 months and throughout the athlete's lifetime was very high. The highest prevalence of injury was experienced by volleyball and handball athletes, although the most serious impact of injuries was reported by football (soccer) and handball athletes. Joint injuries appeared to be the most common type of sports injuries resulting in about half of all athletes taking more than 10 days off practice. Wearing protective gears was found to be positively associated with the history of injury, perhaps because athletes became more careful once they suffered from an injury. Sociodemographic characteristics, general health status, and lifestyle were not associated with sports injuries.

In order to determine the incidence of sports injuries and to establish the temporal association between sports injuries and different predictors, a cohort study is recommended. Also, an assessment of playgrounds and training programs should be done. If these are found to be contributors to sports injuries, necessary preventive actions should be taken.

\section{References}

1 Olsen OE, Myklebust G, Engebretsen L, Holme I, Bahr R: Exercises to prevent lower limb injuries in youth sports: cluster randomized controlled trial. BMJ 2005;330:449.

-2 Tiirikainen K, Lounamaa A, Paavola M, Kumpula H, Parkkari J: Trend in sports injuries among young people in Finland. Int J Sports Med 2008;29:529-536.

-3 Burt CW, Overpeck MD: Emergency visits for sports-related injuries. Ann Emerg Med 2001;37:301-308

$\checkmark 4$ Yde J, Nielsen AB: Sports injuries in adolescents' ball games: soccer, handball and basketball. Br J Sports Med 1990;24:51-54.
5 Schneider S, Weidmann C, Seither B: Epidemiology and risk factors of sports injuries multivariate analyses using German national data. Int J Sports Med 2007;28:247-252.

6 Stevenson M, Finch C, Hamer P, Elliott B: The Western Australian sports injury study. Br J Sports Med 2003;37:380-381.

7 Al-Hadlaq A, Buhamrah A, Al-Omar O, AlKhaldi S, Jevremovic I: Football injuries among recreational football players in $\mathrm{Ku}$ wait; unpublished students project, Kuwait University, 2004.

8 Gabbe B, Finch C, Bennell K, Wajswelner H: How Valid is a Self Reported 12 Month Sports Injury History? Br J Sports Med 2003; $37: 545-547$
9 Schneider S, Seither B, Tonges S, Schmitt H: Sports injuries: population based representative data on incidence, diagnosis, sequelae, and high risk groups. Br J Sports Med 2006; 40:334-339.

-10 Aaltonen S, Karjalainen H, Heinonen A, Parkkari J, Kujala UM: Prevention of sports injuries: systematic review of randomized controlled trials. Arch Intern Med 2007;167: 1585-1592.

11 Emery C: Risk factors for injury in child and adolescent sport: a systematic review of the literature. Clin J Sport Med 2003;13:256268. 